\title{
Creating a Culture of Physician Event Reporting Through Resident Physician Education and Engagement
}

\author{
Jennifer M. Schmidt, $M D^{\top} \oplus$, Justin Adams, $M D^{2}$, and Kathlyn E. Fletcher, MD, MA ${ }^{3,4}$ \\ 'Department of Internal Medicine, Saint Louis University, Saint Louis, MO, USA; ${ }^{2}$ HealthFirst Bluegrass, Lexington, KY, USA; ${ }^{3}$ Department of Internal \\ Medicine, Medical College of Wisconsin, Wauwatosa, WI, USA; ${ }^{4}$ Clement J. Zablocki VAMC, Milwaukee, WI, USA.
}

J Gen Intern Med 35(1):389-91

DOI: $10.1007 / \mathrm{s} 11606-019-05371-2$

(c) Society of General Internal Medicine 2019

\section{BACKGROUND}

Adverse event (AE) reporting is an essential part of patient safety. However, physicians are very unlikely to report. The literature suggests that an institutional culture that embraces safety and quality is essential to supporting physician event reporting. ${ }^{1,2}$ Additionally, reporting increases when physicians receive feedback on the actions that are taken as a result of their error reports. ${ }^{3}$ This project sought to increase reporting among internal medicine residents.

\section{METHODS}

\section{Study Design}

This study occurred between September 2015 and March 2016 and was designed with four 1-month-long plan-do-study-act (PDSA) cycles, each introducing a new intervention. ${ }^{4} \mathrm{We}$ continued each intervention in subsequent cycles. While each intervention was tentatively planned at the start of the project, we analyzed the results of each set of short surveys to determine if we needed further interventions, no further need if 2 months of statistically significant changes occurred in at least two questions. Two 1-month-long sustain and spread cycles were completed after the fourth PDSA cycle. This study was deemed an exempt QI project.

\section{Participants/Setting}

Participants included all house staff rotating on an internal medicine service at the Milwaukee Veterans Administration Hospital (VA) during the study period.

\section{Interventions}

We implemented four interventions (Table 1) including (1) presentation at the program's weekly didactic session, (2) informal event reporting discussions led by chief residents,

Received May 28, 2019

Revised July 16, 2019

Accepted September 12, 2019

Published online October 21, 2019
(3) reporting demonstrations, and (4) feedback on reported events.

\section{Data Collection and Analysis}

We used surveys to collect pre-post knowledge, attitudes, beliefs about barriers to reporting, and VA-specific reporting behavior from the entire residency program. We also used very brief monthly surveys of residents rotating at the VA to assess knowledge of the reporting system and whether or not they reported an event. We used two-tailed chi-square tests $(P<$ $0.05)$ to analyze our data.

\section{RESULTS}

A total of 96 (response rate 77\%) and 91 (response rate 73\%) residents completed the pre and post surveys, respectively.

The monthly survey results as well as the pre/post-project survey results can be seen in Table 2 . The number of residents who reported filing an event report statistically significantly increased for both near misses and adverse events in the prepost analysis. The number of residents witnessing both event types was not statistically significantly different.

\section{DISCUSSION}

We demonstrated increased self-reported filing of patient safety events at the VA. We also saw increased resident physician knowledge of the event reporting system and how to use it. The study team used barriers identified by our pre survey (e.g., awareness of the system and knowledge of how to report) to develop interventions specific to our program. Despite using multiple, targeted measures, achieving and sustaining change required significant effort and time by the project team and leadership. We believe the key to our success was the involvement of leadership, specifically the chief residents. The literature shows that leaders who demonstrate a commitment to event reporting/patient safety are critical to project success and sustainability. ${ }^{5}$ Our chief residents served as reporting role models and encouraged reporting during informal interactions with the residents. We anticipate that sustaining this reporting response will require consistent, continued effort 
Table 1. Interventions

\begin{tabular}{|c|c|}
\hline Intervention & Description \\
\hline Presentation/e-mail & $\begin{array}{l}\text { - Introductory lecture of the ePER* system } \\
\text { presented at required weekly didactic session } \\
\text { - Detailed background on event reporting and } \\
\text { its relationship to physicians (including } \\
\text { commonly cited reporting barriers), } \\
\text { definitions, and examples of near misses and } \\
\text { adverse events } \\
\text { - Directions on filing an event report at the } \\
\text { VA (ePER) including screenshots of each } \\
\text { step of the ePER, as well as tips to address } \\
\text { frequently asked questions/common pitfalls } \\
\text { - E-mail to all residents rotating at the VA on } \\
\text { the first day of the month } \\
\text { o Included the following: introductory } \\
\text { presentation and instructions on how to file } \\
\text { an event report } \\
\text { o Contact information for questions } \\
\text { o Sent out each month of the project }\end{array}$ \\
\hline $\begin{array}{l}\text { Event reporting } \\
\text { discussion/posters }\end{array}$ & $\begin{array}{l}\text { - Chief residents took opportunities during } \\
\text { their informal rounds ( } 3 \text { to } 4 \text { times per week) } \\
\text { to suggest filing event reports, if appropriate, } \\
\text { and assisting residents in completing event } \\
\text { reports } \\
\text { - Discussed event reports at noon conference } \\
\text { - Placed posters in each ward team room; } \\
\text { included definitions of "near miss" and } \\
\text { "adverse event" and instructions how to file } \\
\text { a report }\end{array}$ \\
\hline Reporting simulation & $\begin{array}{l}\text { - Study team demonstrated how to complete } \\
\text { an event report (using a training environment } \\
\text { patient) with residents during a regularly } \\
\text { scheduled conference }\end{array}$ \\
\hline $\begin{array}{l}\text { Feedback on reported } \\
\text { events }\end{array}$ & $\begin{array}{l}\text { - Morbidity and mortality conference based } \\
\text { on a resident-entered event report and the } \\
\text { root cause analysis (RCA) that resulted } \\
\text { - Personal feedback/follow-up, either in } \\
\text { person or via e-mail, if resident self-identified } \\
\text { in the event report } \\
\text { - } 2 \text { general feedback sessions highlighting } \\
\text { outcome/system changes that resulted from } \\
\text { reports }\end{array}$ \\
\hline
\end{tabular}

*Electronic patient event report (ePER) is the system used at our VA Medical Center in reporting adverse events

and engagement of leadership. To most effectively continue resident reporting, we believe the chief residents must continue program-wide interventions. With time, secondand third-year residents should assume some of the onthe-ground event reporting teaching and rolemodeling - this would demonstrate a true, integrated culture of reporting. While multiple labor-intensive interventions were required to obtain and maintain a statistically significant change, we believe that our study demonstrates how to create a foundation on which to build a sustainable reporting culture within a residency program.

The two major limitations of this study are that it occurred at a single site and that the event reporting was self-reported. Our event reporting system did not allow us to identify whether reporters were residents, making it impossible for us to track trends in actual reporting. In summary, even though traditionally, physicians do not report events, ${ }^{1,6}$ we demonstrated that targeted, low tech efforts addressing event reporting barriers can increase physician event reporting.

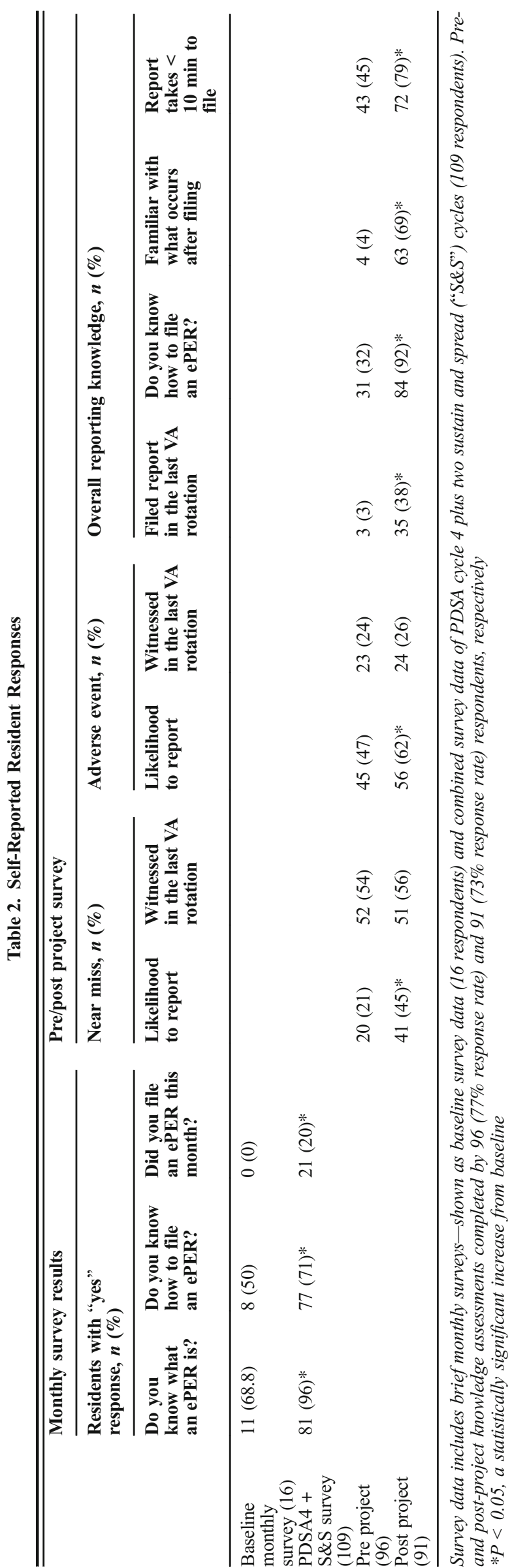


Corresponding Author: Jennifer M. Schmidt, MD; Department of Internal Medicine Saint Louis University, Saint Louis, MO, USA (e-mail: Jennifer.merlo.schmidt@gmail.com).

\section{Compliance with Ethical Standards:}

Conflict of Interest: The authors declare that they do not have a conflict of interest.

\section{REFERENCES}

1. Kaldjian LC, Jones EW, Wu BJ, Forman-Hoffman VL, Levi BH, Rosenthal GE. Reporting medical errors to improve patient safety: a survey of physicians in teaching hospitals. Arch Intern Med 2008; 168(1):40-46.
2. Wachter RM, Shojania KG, Markowitz AJ, Smith M, Saint S. Quality grand rounds: the case for patient safety. Ann Intern Med 2006; 145(8):629-630.

3. Leape LL. Reporting of adverse events. N Engl J Med 2002;347(20):16331638.

4. Taylor MJ, McNicholas C, Nicolay C, Darzi A, Bell D, Reed JE. Systematic review of the application of the plan-do-study-act method to improve quality in healthcare. BMJ Qual Saf 2014;23(4):290-298.

5. Appelbaum NP, Dow A, Mazmanian PE, Jundt DK, Appelbaum EN. The effects of power, leadership and psychological safety on resident event reporting. Med Educ 2016;50(3):343-350.

6. Rowin EJ, Lucier D, Pauker SG, Kumar S, Chen J, Salem DN. Does error and adverse event reporting by physicians and nurses differ? Jt Comm J Qual Patient Saf. 2008;34(9):537-545.

Publisher's Note Springer Nature remains neutral with regard to jurisdictional claims in published maps and institutional affiliations. 